\title{
Facilitating creativity in dementia care: the co-construction of arts-based engagement
}

\author{
Jane M. Robertson* and Vikki McCall \\ Faculty of Social Sciences, University of Stirling, Stirling, UK \\ ${ }^{*}$ Corresponding author. Email: j.m.robertson@stir.ac.uk
}

(Accepted 30 October 2018; first published online 5 December 2018)

\begin{abstract}
This paper seeks to understand the engagement of people with dementia in creative and arts-based activities by applying a relational model of citizenship and incorporating concepts of contextual and embodied learning from adult learning theory. A theoretically driven secondary analysis of observational and interview data focuses on the engagement of staff, volunteers and people with dementia during an arts-based intervention in a day centre and care home. The processes through which learning is co-constructed between the person with dementia, staff/volunteer facilitators and peers in the group to co-produce a creative engaged experience involves: increasing confidence for learning, facilitating social and physical connections, and affirming creative self-expression. The role of facilitator is central to the process of creative engagement to reinforce a sense of agency amongst participants and recognise people's prior experiences of learning and engagement in creative activities. People with dementia continue to learn and grow through engagement in creative activities to produce positive outcomes for the individual participants and for the care staff who observe and participate in this creativity. Facilitating creativity requires attention to lifelong experiences of learning in addition to the immediate interactional context to integrate arts-based interventions in dementia care successfully.
\end{abstract}

Keywords: adult learning; arts; creativity; dementia care; engagement; participation; relationships; social interaction

\section{Introduction}

The link between 'the arts' and dementia care is a growing area of interest as people look for innovative ways to deliver positive health and social care outcomes. This paper reflects critically on the process of facilitating creativity during an artsbased intervention to focus on the co-constructed learning processes between the person with dementia, staff/volunteer facilitators and peers in the group. In exploring the impact of an arts-based intervention to engage people with dementia in conversation and social interaction, we advocate a critical approach to understand the context of this creative engagement within a relational model of citizenship that applies concepts from adult learning theory. We discuss how 
engagement in arts-based activities can be linked to contexts of lifelong learning for people with dementia.

\section{Dementia and the arts}

Recent reviews of dementia and the arts have demonstrated positive affective and quality-of-life outcomes for participants, such as increased confidence, engagement, self-esteem and social participation, which are linked to the social support inherent in group arts instruction and the well-researched benefits of involvement in engaging and productive activities (Noice et al., 2014; Zeilig et al., 2014). Opportunities for intellectual stimulation and social inclusion are reported to create positive emotional and relational effects for both people with dementia and their carers (Camic et al., 2016). In addition to social and communicative aspects of engagement, arts-based activities can have a positive impact on cognitive engagement (Young et al., 2016) as they are considered helpful to support personhood and stimulate cognitive processes of attention and concentration (Gould, 2013; Camic et al., 2017). Further, embodied forms of the arts provide opportunities for connecting with non-verbal forms of communication and expression (Nyström and Lauritzen, 2005; Hamill et al., 2011). Consequently, Killick and Allan (2001) have proposed that the arts offer the potential for a person-centred approach as they support self-expression, communication, occupation, creation and therapy.

Increasing interest in the role of the arts in dementia care parallels wider academic and policy discourses in the cultural sector around everyday participation and cultural value, with an emphasis on social inclusion and understanding the social relations of participation and production (Miles and Gibson, 2016). Participatory forms of engagement may be helpful for supporting people with more advanced dementia to connect to emotional and physical memories (Zeilig et al., 2014), whilst combining different forms of arts-based activities can be beneficial for supporting a sense of self and preserving individual identities in groupbased interventions (Beard, 2011). The literature in this area of dementia care is therefore overwhelmingly positive about the potential outcomes of the arts; although as de Medeiros and Basting (2014) emphasise, participants are likely to be affected in very different ways by the same intervention. Similarly, Coleman (1986) and Mackenzie (2009) have highlighted the need for greater awareness of diverse responses and social contexts when delivering interventions associated with reminiscence or life story work.

Despite the prevailing emphasis on the positive potential of the arts to engage people with dementia successfully, the need for robust qualitative methodologies has been highlighted as a priority for the evaluation of arts-based interventions (Daykin et al., 2017). Observational and interview research are important methods for evaluating process and experiential outcomes to develop an evidence base for arts-based intervention (Clift, 2012). Understanding the ways in which people experience their engagement with arts and how this engagement impacts on creativity in everyday practice are particular priorities within the wider cultural sector (Crossick and Kaszynska, 2016). Furthermore, the need to understand the processes involved in arts-based engagement as well as outcomes has been highlighted as 
significant for research in the field of dementia due to the complexity of the wider environment and context in which interventions are delivered (Goulding, 2013; Harries, 2013).

Haslam et al. (2014) have argued that participants' sense of social identification is an important predictor of success in an arts-based intervention, with a lack of identification with the group linked to increased anxiety. Additional factors identified as important in the wider environment that impact on the experience of artsbased activities for people with dementia include: the facilitation process, social interaction with participants, and past (positive) experience of the arts reflected in active participation and engagement (Burnside et al., 2017).

The social context of learning therefore plays an important role in how adults approach and learn new activities (Merriam and Bierema, 2013). Merriam and Bierema (2013) emphasise the importance of understanding a person's life situation and the implications this has for their learning, including the social roles and psycho-social tasks associated with their lifestage. Like other adults, for people with dementia engaging in arts-based activities their lifelong experiences act as both stimulus and resource for learning. A particular benefit of arts-based approaches for people living with a progressive condition may be an emphasis on retained strengths and abilities, as opposed to deficits and loss (Tietyen and Richards, in press). 'Failure-free' activities that maximise residual capacities are most likely to create confidence and feelings of mastery (Windle et al., 2018b). In addition to enjoyment and pride amongst participants developing from an increased sense of competence, evidence of people with dementia learning new activities can be helpful for promoting positive expectations amongst care staff (Camic et al., 2016) and providing opportunities to interact outside their usual professional role (Guzmán-García et al., 2012).

Settings where people learn also impact on experiences, with places like day centres and care homes defined as 'non-formal' settings since learning is supported by organisations whose primary purpose is other than educational (Merriam and Bierema, 2013). Adopting the overarching concept of 'lifelong learning' recognises the complexity of learning across the lifecourse that includes the interplay of formal, non-formal and informal settings in shaping experiences (Aspin et al., 2012) and the application of previous experiences to new situations (Dewey, 1963). These prior experiences create opportunities as well as barriers for learning (Knowles et al., 2011). Gray et al. (2018) highlight the importance of understanding the role of complex contexts in the evaluation of arts-based interventions for people with dementia, while Broome et al. (2017) evidence the effect of the environment on the facilitation process. Therefore, both the social and physical environment combine to impact learning experiences.

While it is often assumed that adults are independent and self-directing in their learning, people with dementia are likely to require particularly skilled facilitation. Knowledge and expertise about both the arts and dementia are key contextual factors in successful facilitation of arts-based activities for people with dementia (Windle et al., 2018a). Similarly, Humphrey et al. (in press) refer to three components of successful arts-based engagement for people with dementia: an appropriate dementia-friendly physical environment, supportive and participatory communication strategies, and suitable activities that focus on experiences rather than outputs. 
Gradually increasing the challenge and complexity of engagement and providing multi-modal stimulation have also been cited as important dimensions of facilitating a successful learning experience for people with dementia (Tietyen and Richards, in press).

Consequently, the social, physical environment and facilitation process impact on learning and arts-based engagement. 'Contextual learning' is a model of experiential learning that emphasises the place and interactional context in which learning occurs, in addition to the tangible resources that people have to hand (Merriam and Bierema, 2013). The intersection between learner and context is therefore prominent in this model. While cognitive models of learning have dominated in earlier models of adult learning theory, embodied learning is receiving increasing attention; this is particularly salient to arts-based engagement for people with dementia since it extends the experience of learning and participation beyond cognitive processes. Embodied learning conceptualises the body as a site of learning and recognises the significance of movement and sensorimotor experiences for coming to know ourselves and the world around us (Stolz, 2015). Dirkx (2001: 64) places particular emphasis on the emotional dimension of embodied learning: 'personally significant and meaningful learning is fundamentally grounded in and is derived from the adult's emotional, imaginative connection with the self and with the broader social world'.

Embodiment as a concept in the field of dementia similarly recognises the significance of corporeality as a fundamental source of self-expression, interdependence and reciprocal engagement (Kontos and Grigorovitch, 2018). The perspective of embodied learning is helpful for exploring arts-based engagement for people with dementia given the importance of attending to the social context and engaging with retained capacities, as discussed above. Emphasising the emotional and relational dimensions of selfhood within embodied learning connects to the concept of 'embodied selfhood' used by Kontos (2004) to define the prereflective sources of perception that persist in a person despite severe cognitive impairment. Similarly, Ullán et al. (2011) recognise the importance of intersubjective and relational aspects of learning through arts-based engagement to support feelings of empowerment. Conversely, recognising embodied expressions of resistance may be equally important to understand how people with dementia influence arts-based engagement, and to acknowledge the potential for artsbased engagement to produce both positive and negative emotions within a relational context that includes attention to relations of power (Bellass et al., in press).

With active engagement and participation a central feature of policy and practice in dementia care (Mental Health Foundation, 2015), agency and strength-based frameworks within arts-based activities can help to promote person-centred care (Bienvenu and Hanna, 2017) and social citizenship (Basting, 2018). Kontos et al. (2017) extend the concept of social citizenship by promoting a relational model of citizenship that is inclusive of people with severe cognitive impairment who can continue to engage with the world through meaningful physical interaction. They argue that creativity is a key way in which people with dementia communicate since it is a visible manifestation of relationality and embodied selfhood through which citizenship may be achieved (Kontos et al., 2017). Thus, arts-based 
engagement can support 'embodied creative agency' (Bellass et al., in press). Given the importance of skilled facilitation in supporting arts-based engagement for people with dementia, a contextual model of learning can be applied to understand how participants and facilitators interact to co-construct creative arts-based engagement in care settings.

\section{Design and methods}

The paper presents the secondary analysis of qualitative data from a project in 2016 that explored the impact of a creative activity toolkit designed by a social enterprise to support participatory arts-based activities for people with dementia in day centre and care home settings. The toolkit included a range of activities, including music, poetry and visual arts, to promote conversation and social interaction. The original analysis focused on: (a) evaluating whether the toolkit delivered the intended benefits of prompting reminiscence and supporting constructive conversation to engage with personal histories and build social connections; and (b) identifying improvements that could enhance impact in these areas. Given the observed significance of the social context in co-constructing this arts-based engagement, a secondary analysis was conducted to explore the relational processes between the person with dementia, staff/volunteer facilitators and peers in the group as they participated in arts-based activities.

\section{Participants and settings}

Observations took place in a day centre and a residential care home that had prior experience of using the toolkit. The toolkit was designed by artists and developed by a social enterprise with the aim of supporting activity coordinators, care staff and volunteers to deliver tested arts-based activities. The toolkit is designed as a complete guide that supports in-house facilitators to deliver arts-based activities independently by providing a framework of activities that guides facilitators in planning and structuring a series of sessions focused on the topic of gardens. While activities were mostly arts-based, these were complemented with creative and practical activities associated with gardening, plants, etc. Access to conduct fieldwork in these settings was approved by the local authority and third-sector organisation running these care services. Observations were conducted with people with dementia $(\mathrm{N}=28)$, day centre and care home staff $(\mathrm{N}=8)$ and day centre volunteers $(\mathrm{N}=7)$. Interviews were conducted with team leaders $(\mathrm{N}=2)$ and staff who had led activity sessions $(\mathrm{N}=5)$. Both care setting locations are ranked in the middle quintile of 'deprived data zones' in the Scottish Index of Multiple Deprivation (Scottish Government, 2016) where this research was conducted. Given the connections between culture, class and art (Bourdieu, 1984) that can lead to situational differences in engagement with arts-based interventions, this could indicate that participants were from similar populations that were neither economically deprived nor affluent. However, since we did not collect demographic information, such as the social class or ethnicity of participants, we cannot be certain as to the effects of diversity on engagement. 


\section{Ethical considerations}

Informed consent was obtained from all participants. Consent for involving participants, staff and volunteers was established at the start of each session following Dewing's (2007) ongoing consent process. This process began with familiar care staff in the care home and day centre settings establishing initial interest amongst potential participants. All participants who had indicated their interest were given an information sheet. Researchers ensured this had been understood by each individual before asking them to provide formal consent. Written consent was obtained from staff and volunteers. Verbal consent from participants was digitally recorded as some participants had difficulty with writing. Assent from a relative of each participant was additionally obtained by the team leaders in each setting prior to observation sessions. During observations, researchers used orientating statements to remind participants that they were conducting an observation for the purposes of research, while monitoring both non-verbal and verbal cues that might indicate a person was uncomfortable or unwilling to continue participating. Anonymity and confidentiality were guaranteed by replacing names with participant codes in observation notes and interview transcripts. In the findings below, interview data are indicated with participants coded A-D to ensure that confidentiality and anonymity is protected. Observation data indicate the date and location of the observation.

\section{Primary data gathering and analysis}

Fieldwork involved observation of the toolkit being used in the two care settings followed by interviews with staff who had facilitated the sessions and team leaders who had overall responsibility for planning the sessions. Each observation was conducted by two non-participant researchers using an observation framework developed from Spradley's (1980) techniques of observation to research ethnography and culture. In addition to recording verbal and non-verbal interactions between participants, staff and volunteers within each setting, the following dimensions of the environment were recorded as relevant context for these interactions:

- Space: layout of the physical setting: rooms, outdoor spaces, etc.

- Actors: the names (coded) and relevant details of the people involved.

- Activities: the various activities of the actors.

- Objects: physical elements: furniture, etc.

- Acts: specific individual actions.

- Events: particular occasions, e.g. meetings.

- Time: the sequence of events.

- Goals: what actors are attempting to accomplish.

- Feelings: emotions in particular contexts.

- Impairments: impact of sensory impairments, mobility problems or other access requirements.

Field notes were the key method of data collection, with two sets from each session helping to cross-check and verify observations. The notes included: running descriptions, ideas remembered at various times, ideas and provisional 
explanations, personal impressions, and feelings and actions to follow up as recommended by Gillham (2000). This framework provided a structure for observation exploring processes and immediate outcomes without constraining the potential to observe unanticipated effects. Following Spradley's (1980) technique, the researchers made maps of the environments that were being observed. This emphasised the importance of the physical space and how it affected social interaction and facilitation. In consequence, a holistic picture of 'tacit' and 'explicit' cultures and assumptions (i.e. what people found easy and also difficult to communicate) were captured.

Additionally, interviews were undertaken with staff $(\mathrm{N}=7)$ to gain their perspectives on using the toolkit in their care setting. A topic guide set out key questions that explored perceived benefits, opportunities and limitations of using the toolkit for group arts-based activities. Interviews were digitally recorded and transcribed.

The first set of observations took place over three weeks in the day centre: six sessions with an average of five participants per session. A total of 21 people with dementia and 13 staff (three day centre organisers, three support staff and seven volunteers) were observed participating in arts-based creative activity sessions. The second set of observations was conducted in the care home over two weeks: four observation sessions with four participants per session. A total of seven people with dementia and two care staff (one activities co-ordinator and one care assistant) were observed. Interviews were conducted with one day care organiser, one day care worker and one day care team leader; and one activities co-ordinator, one care worker and one team leader in the care home.

During observations, interesting notes, thoughts or analysis were written down as field notes in a notebook. After each session a 'de-brief' was conducted between the two observers to begin analysis and record themes within the observation framework. This supported the triangulation of data between the two researchers and the observation framework as well as started the coding process for analysis. The framework data were then brought together for initial coding and thematic analysis, including cross-analysis and re-checking of data between observers. Interviews were transcribed verbatim and reviewed for themes relevant to the observation framework, in addition to looking for new themes that emerged from the data to understand the impact of the toolkit, and any potential limitations, barriers or important context for its use.

\section{Data analysis}

A secondary analysis of the data (Heaton, 1998) was conducted by the same researchers who conducted the primary analysis. The secondary analysis focused on how the relational context, including facilitation by staff and volunteers, and interaction between peers, influenced creative engagement and active participation in arts-based activities. While the initial analysis had explored participation and facilitation of arts-based engagement to evaluate the impact of the intervention, the data had not been analysed to investigate the co-constructed experience of this engagement in depth.

A new set of questions guided the secondary analysis to explore: 
- What aspects of the relational context in care settings facilitate creative engagement and participation in group activity sessions?

- How is learning co-constructed between peers, care staff and volunteers to support creative engagement and participation in group activity sessions?

Initial thematic analysis involved looking across the data-set for repeated patterns of meaning. Following the process set out by Braun and Clarke (2006), the researchers independently read the observation notes and interview transcripts to generate initial codes. Once these data were examined, the researchers worked together to sort the codes into themes and sub-themes to generate a descriptive thematic map of the analysis. Themes were defined and refined following discussion between researchers about any discrepancies in coding. The main themes generated from this process were: facilitating positive engagement through humour, levels of confidence and anxiety amongst participants, confidence and interaction with facilitators, supporting agency and self-expression, affirming and validating identity, negotiating activities with participant-led conversation. Following this initial analysis, the literature was reviewed to relate the identified themes to relevant theoretical constructs and frameworks around adult learning, arts-based approaches and dementia care. From this theoretically driven analysis, the following themes were developed: increasing confidence for learning, facilitating social and physical connection, and affirming creative self-expression.

\section{Methodological limitations}

As an exploratory paper that draws on data from two care settings, its generalisability is limited. More in-depth data from individual participants would have enabled differences to be explored between, for example, people with varying levels of cognitive ability (Young et al., 2016) and different levels of cultural capital (Bourdieu, 1984).

\section{Findings}

\section{Increasing confidence for learning}

Skilled facilitation was a subtle but significant feature of supporting creative engagement in arts-based activities within a dementia care setting to increase confidence for new learning. Attention to both the physical setting (good lighting and sufficient space for participants to move around during activities) and the social environment (ensuring participants were seated at the same level and could maintain eye contact with each other) was conducive to starting sessions effectively. Involving participants in setting out the materials to get ready for an activity session was observed to be helpful in supporting people to move around and become physically involved, which helped both to make people feel an active part of the process and to ease people into the creative activities by first participating in practical arrangements. In addition to putting people at ease at the start of an activity that was new to them by involving them in a more familiar activity (setting out a table with either refreshments or materials), this contribution appeared to create a sense of accomplishment at the very outset of the session. 
In settling participants, facilitators first engaged in reminiscence to involve people in sharing conversation. This reminiscence helped to reduce initial anxiety. Whilst all participants had consented to participate, some people verbalised anxiety around taking part in a new activity. For example, one participant repeatedly commented at the start of a session that she was 'thick as two short planks' and would not be able to contribute to the session. By the end of the session, when she was colouring and singing with other participants, she exclaimed while laughing that she was 'doing two jobs at once, I'm smart, wish I'd been as smart at school' (Day Centre, 13 April 2016). This engagement had followed initial reminiscence about plants and nature started by the facilitator. The participant then moved the conversation on to stories of her childhood and connections with nature where she grew up. During this reflection she started singing the first lines of a popular song from this era, which prompted the facilitator to find the associated music on her tablet and encourage the whole group to join in with singing. From this point onwards, the atmosphere in the day centre relaxed and the facilitator introduced the group to visual arts activities, relating images to aspects of the stories just told.

Easing participants into an activity that was new to them and supporting the person to feel a sense of mastery and competence were important in the context of lifelong experiences of learning. Comments emphasising a lack of confidence were not uncommon. As indicated in the quote above, negative associations with school could be a barrier to engagement, linked to negative self-talk or reluctance to engage in activities. For example, in one session a participant described the activity (where they were talking about gardens) as being like 'coursework' (Day Centre, 14 April 2016). While some participants appeared concerned about not being sufficiently artistic or creative, others appeared to be worried about 'getting it right' more generally. Fear of failure associated with changing cognitive abilities appeared to be important context for people with dementia. One facilitator reflected on several participants looking for reassurance that they were not being assessed or tested (in the context of being regularly assessed for alcohol-related dementia), while other people attending the day centre had declined to participate due to a fear of failing at the activities:

And the other thing of note was how many people thought they were being tested, they were asking for reassurance, did we pass? Was that okay? It was certainly evident in people who go to the memory clinic ... Because some staff members said initially, these individuals are usually very chatty, and they were very reticent, and we certainly know one declined to take part, but certainly had a lot to say later on, and that was because he didn't want to fail. (D, Day Centre, 17 May 2016)

In addition to the immediate social context, the wider context of dementia care therefore influenced these participants' experiences and expectations of engagement in arts-based activities. Anxiety could also be associated with early experiences of the arts, which could impact on a person's level of engagement and enjoyment in creative activities during group sessions. For example, participants would ask if they were doing a task right, asking 'is it okay?' in the midst of reading poetry before continuing (Care Home, 5 May 2016) or being worried that a picture 
they made was 'not fit to show' (Day Centre, 11 April 2016). In such instances, encouragement by the facilitator was important to ease such anxiety and increase confidence in abilities. Similarly, confidence appeared to flourish within a group context where those who were nervous about their abilities or hesitant to become involved in creative activities could watch their peers engage without pressure from the facilitator to join in the activity. Being able to observe and participate on their own terms and in their own time was important when trying a new activity. In addition, for participants who were quieter, the group-based nature of activities was helpful to create confidence by providing a structure through which to share stories and memories, as reflected by this facilitator:

Yes, I think it brought it out quite a bit, especially within the group, because some people are quieter in the group, and some people prefer one-to-one activities. But I thought, as a whole, it brought out a lot of good conversation. And people who are usually on the quiet side joined in with a lot of the conversation, their stories and memories sort of thing. The group activity promotes their conversation and social skills, and gives them a wee bit more confidence. (B, Day Centre, 5 May 2016)

While a supportive peer group was important for positive engagement, the connection between facilitator and participants was equally significant. During reminiscence before and during the arts-based activities, the sharing of personal stories between facilitators and participants encouraged a sense of everyone being on the same level, rather than having a sense of clearly defined roles of service user and provider. The facilitator would get the session started and lead activities based on their planning and preparation but creative engagement seemed most successful when participants as well as staff could guide the activity and shape the session. In this sense, a participatory approach was enabling: the skill of the facilitator was in the subtle and gentle introduction of themed topics that could then be explored through creative engagement that allowed room for participant agency.

As well as creating benefits for participants, seeing people with dementia engage with creative activities could be helpful for promoting higher expectations amongst staff around the capacity for self-expression, as reflected in the quote from this facilitator in the day centre when reflecting on the high level of engagement and participation she observed:

I was really surprised by the art work, the colouring-in, because it mentions about self-expression. And we would like to do a lot of artwork [beyond the intervention] but we need to bear in mind that not everyone wants to do it. But we are actually normally limited in the amount of people who want to do it. So I actually saw people colouring-in, that I was really surprised that they did that, I wasn't expecting them to pick up the pen, but they did that and colour-in. So that was really good from our point of view, just seeing that. (A, Day Centre, 5 May 2016)

There were also examples of activities being helpful in increasing confidence among staff in relation to adopting a new role in their workplace. At one session, a member of the care staff who had facilitated the session alone - having not previously led these types of activities with such sessions in the care home usually being delivered 
by the activities co-ordinator - commented that she was 'not used to delivering activities, and I'm finding I really enjoyed this, it's given me confidence to do more' (Care Home, 6 May 2016). Her enthusiasm and skilled interaction with participants produced a very positive session despite her lack of formal experience or training in leading creative activities. Her knowledge of participants' life histories from working in the care home and her skilled ability to engage participants with varying levels of dementia appeared to be the most important aspects of her skilled facilitation. She wanted to become involved in creative activities as a more routine element of care, so that she could deliver activities with residents outside planned activity sessions.

Lack of confidence around learning a new activity was sometimes mirrored by those facilitating the sessions when they underplayed or undermined their own creativity. For example, one volunteer stated: 'I was rotten at art at school, good with a set-square' (Day Centre, 7 April 2016). At another session, a volunteer noted that he 'isn't good at art as I've no imagination', while a member of staff reflected 'we're all amateurs' (Day Centre, 11 April 2016). In these examples, a lack of comfort is clearly evident around engaging in arts-based activities that is related both to past experiences of education and expectations around creativity. As facilitators gained experience of supporting activities, their confidence grew across sessions.

\section{Facilitating social and physical connection}

Social interaction and participation is therefore an important component of engagement in creative activities for participants as well as a central outcome of arts-based activities in a group setting: arts-based activities could be useful for promoting positive social interaction, while a supportive social context enabled participants to engage creatively. Some participants appeared to benefit from focusing on a structured group activity to support them in feeling comfortable sitting with others and interacting more fully with other participants. Connecting via a shared activity helped people to be physically involved in the session, even if their dementia had progressed to the point where they were less involved in direct conversation:

This is good; she doesn't usually sit for more than five minutes. (Staff member to another staff member, Day Centre, 11 April 2016)

I was quite surprised at [name]. I've never known her sit so long. She sat for the whole session that day. So that, kind of, and she interacted probably better than she had done. (A, Care Home, 19 May 2016)

The positivity of a group dynamic could therefore encourage people to participate when previously they had been less engaged in a care setting. As well as the use of reminiscence as an activity to develop connections amongst the group, elements of humour were important for facilitating positive social connections. Humour played an integral part of peer interactions, to connect with creative activities and to solicit reactions, in particular the satisfaction of making the group laugh. This humour was carried through subtly using different types of body language (with nudges 
and raised eyebrows) and played a large part in building a natural dynamic and flow into conversations, including clear actions to bring others into these interactions. Humour therefore appeared to be especially helpful for developing a positive dynamic when it was participant-led, such as in the following example:

[Facilitator reminds everyone about the last session and asks about the garden shed]

Facilitator: What did you keep in there?

Participant A: Teeth! (everyone laughs)

Volunteer 1: Did you hide in there when your wife was on the rampage?

Participant A: Aye! (everyone laughs)

Participant B: The garden shed used to be somewhere to store the cans [of beer] when I went out to work and get a swally [drink] every ten minutes. (everyone laughs) (Day Centre, 11 April 2016)

While volunteers and care staff mostly helped facilitate this type of humour, on occasion facilitators tried to play it down if they saw it as going 'off task' from the creative activity. Conversely, participants could subvert creative activities for humorous effect, which might have been associated with unease about the activities. For example, in the midst of passing around plants and fruits during a sensory group activity, one participant placed a dock leaf on his head and sat, smiling, looking ahead, joking about what he was doing rather than engaging with the facilitator's plan to explore the sensory aspects of the plant (Day Centre, 20 April 2016). As such, this resistance was important in influencing the direction of participation. Even if a person chose not to engage, feeling a sense of agency about participation was an important element of the interaction between staff and participants during sessions. The key for successful arts-based engagement was in letting participants co-construct the experience and increase their agency while facilitating the social interaction rather than only the activity.

An important skill in facilitating the session related to the facilitator's capacity to skilfully connect with the participants and introduce activities at a pace that suited them. This enabled participants to have more control of the process, particularly when activities were introduced naturally through conversation. Facilitators skilfully linked reminiscence with creative activities, for instance reminiscing with the group about favourite butterflies after a participant remarked on how beautiful a butterfly looked on one of the resources (Care Home, 5 May 2016). Such reminiscence worked most effectively in the care home setting where staff had good knowledge of people's histories and families, as well as local shared cultural heritage. Another facilitator (Care Home, 19 May 2016) described how she had no knowledge of the activity topic, but used her own memories to develop conversations and connect with memories they generated:

B: $\quad$ You can use your own memories, so I don't think you needed to have an interest.

Interviewer: I thought you did. 
B:

It just shows that how important that is, the reminiscence, the memories, even if it's someone a bit younger, not just older, it's important how it makes you feel.

While the facilitator was leading activities, other staff were observed supporting participants to engage through bringing them into conversations and helping with the creative activities. Consequently, the facilitator was the driver of the process, yet other staff/volunteers were integral to the success of activity sessions: if staff moved in and out of the session a lot, for instance answering the telephone in between helping participants with an activity, this impacted negatively and participants could lose focus (Day Centre, 20 April 2016; Care Home, 19 May 2016). Staff interaction was key to keeping the flow of conversation natural and reinforcing engagement by ongoing praise that kept the participants motivated, while maintaining a connection to the overall theme of the session to create a focal point:

I think it was good to have a focal point. The [activity] was really good and they all focused on that. Rather than just sitting down and having a chat, there was a theme running right through it. It didn't matter if it went off the theme, you could easily bring it right back, and I think that helped with more structure, it was more meaningful, having that theme, and everyone was able to add something to it, I felt, the garden, the flowers, it wasn't just plants, you could bring birds, you could bring sheds, it was good. (B, Care Home, 19 May 2016)

Despite evidence of many positive interactions, there were instances when activities were prioritised over participant-led conversations, and this could have a detrimental effect. When facilitation was too rigid, this could impact negatively on some participants by shutting down their chosen conversation. For example, when staff were trying to push forward an activity in the day centre, one participant had wanted to talk about her family but was overridden and ignored, despite stating several times: 'Do you hear me?' (Day Centre, 14 April 2016). Similarly, when a volunteer interrupted a participant colouring-in and took their picture without asking, the participant said: 'Hey! Give it back! God, you nearly got me upset there' (Day Centre, 7 April 2016). In these instances, the participants tried to assert their agency although the power dynamics of the care setting meant that they could not always maintain a sense of control.

The importance of the connection between facilitator and participant was evident through body language as well as words. For instance, one participant was unsure about taking part in one of the creative activities. This was shown clearly though his body language (arms crossed, leaning back) (Day Centre, 7 April 2016). A volunteer sat beside this participant and started to colour in the sheets in front of him. Slowly, the person with dementia also joined in. Thirty minutes later, the participant and volunteer were still drawing side by side. When the session was due to finish for lunch, they were both reluctant to stop given their immersion in the activity, highlighting the high level of engagement and connection between them both. 


\section{Affirming creative self-expression}

Given the importance of creating a relational context which created confidence for learning and which facilitates social and physical connections, affirming creative self-expression was an important element of this co-constructed experience. Successful engagement in arts-based activities was less about 'the art' as an output and more about the process of engagement facilitated by staff and volunteers. There were two main elements that were central to the co-construction of learning between participants and facilitators: motivation through ongoing praise and the ongoing affirmation of identity reinforced through the arts-based activities.

Building a positive group dynamic also involved staff giving ongoing praise and interest in the participants' lives and activities. The encouragement given to participants by staff and volunteers ranged from encouraging different participants to become engaged to praising 'budding artists' (Day Centre, 14 April 2016). Another key theme from the observation that reinforces the importance of the facilitation process was the ongoing affirmation of the identity of participants, such as moments when the conversation surrounding activities was used by staff to endorse identities. Validating a valued aspect of a person's sense of self was observed as very affirming for participants, as reflected in the following exchange:

[During a session when participants were standing around a table placing soil in tubs and planting bulbs in the soil to create a planter]

Participant: We'll all be gardeners now. (laughing)

Facilitator: You told me you're a gardener.

Participant: Yes, I love gardens. (Care Home, 5 May 2016)

Similarly, while another participant was absorbed in colouring and drawing, the facilitator recognised her creativity as an enduring aspect of her identity: 'in all the years I've worked here, you're the most creative person I know' (Care Home, 10 May 2016). More generally, involving participants in setting up and clearing activities, as discussed above, created a relaxed atmosphere in which participants' capacities were recognised and appreciated to instil a sense of competence (Care Home, 5 and 6 May 2016). The structure of the sessions was therefore helpful for supporting a sense of self-worth and celebrating participants' work, especially when someone was feeling anxious. One member of staff reflected on the value of this approach in relation to a participant who had just started attending the day centre, as they had been concerned she would not settle into new activities due to her initial level of anxiety:

$M$ was here on her first day, and we were expecting her to be really unsettled. But she started colouring-in and she was, just, completely gone, just totally absorbed and enjoying it. And she was so pleased with her result, 'Did I do that?' She was, she was good, very very settled. But I do find the arty work off that, we've copied a lot of them and we're still using them as an art activity [refers to some on the wall]. Because that's going up in the gallery, that's us looking at them, and they get that self-worth. (B, Day Centre, 5 May 2016) 
Feeling a sense of achievement was important, with one participant taking pride in reciting poetry clearly and confidently - stating that 'speaking nicely' was something that had always been important to her (Care Home, 5 May 2016). Consequently, this participant was keen to lead the poetry recital at each of the sessions she attended, asking to come to extra sessions, and thanking/shaking hands with the researchers at the end of the session (Care Home, 6 May 2016).

In co-constructing a positive experience, peer support was an important element of group-based activities. In one session there was a long discussion about creativity and school, with one participant's talents for drawing and interest in poetry being discovered by the support staff for the first time (Day Centre, 7 April 2016). The participant went on to state he never enjoyed poetry at school but did later in life, followed by a joke about the school system: 'I was told I would never amount to anything and I proved them right!' He then recited the poem confidently to a quiet and attentive group who offered positive feedback and affirmation. Participants were often seen to motivate each other actively, with one participant noting to another about her picture: 'that's a touch of class there' (Care Home, 10 May 2016).

Supporting embodied approaches to creativity was also helpful for creative engagement. When people were brought into the activity physically, they sometimes then became more engaged on a verbal level (Day Centre, 15 April 2016). Facilitators reflected on how hands-on activity created a sense of accomplishment and active participation (A, Care Home, 19 May 2016; B, Care Home, 19 May 2016). Engaging in arts-based activities could also spark more physical reactions, such as in one session when a participant remarked 'I'm making a great job' about their colouring, before picking up a trowel on the table and mimicking the action of digging the plant on the colouring-in sheet (Day Centre, 13 April 2016). Encouraging participants to engage with sensory aspects, such as smell and touch, was also perceived to be valuable to create connections and encourage reminiscence (C, Day Centre, 5 May 2016; A, Care Home, 19 May 2016); while facilitation can be important for supporting a person to participate when they have limited mobility, such as when a facilitator assisted a participant to stand while she planted bulbs, highlighting the co-constructed nature of this engagement (Care Home, 5 May 2016).

The physical environment also had an impact on people's creative selfexpression. For instance, one participant was not engaged in activities when sitting around a table indoors (with closed body language and not interacting with other participants or staff). When the facilitator asked if participants would like to go for a walk in the garden, this man joined in. When in the garden he was observed to lead the group along the path looking at flowers; while not talking, he repeatedly smiled, laughed and made eye contact, appearing engaged and happy to be outside in the garden and taking a lead in activities (Day Centre, 14 April 2016).

\section{Discussion}

This paper has focused on experiences of engaging in arts-based activities to consider: (a) how learning is co-constructed between peers, care staff and volunteers to support creative engagement and participation, and (b) what aspects of the 
relational context in care settings facilitate creative engagement and participation in group activity sessions. A supportive relational context facilitated helpful social interaction, confirming evidence that arts-based interventions can have positive relational effects (Camic et al., 2016). As has been established in reviews of evidence around impact, creative activities could increase confidence, engagement and social participation (Noice et al., 2014; Zeilig et al., 2014; Camic et al., 2017). Viewing participants as 'students' using a new set of 'tools' to express themselves individually and collectively frames creative engagement and personal growth within lifelong learning (Grant et al., 2011).

The findings have highlighted the significance of supportive interaction between peers and skilled facilitation by staff and volunteers to increase confidence for learning when taking part in new arts-based activities. The social context of learning plays an important role in how adults approach and learn new activities (Merriam and Bierema, 2013), and this was evident in the current study: people were most engaged when they were eased into creative activities through conversation and reminiscence, and when they were able to participate actively in shaping the sessions by guiding the direction of activities. In this way, experiences of engagement and learning were fostered in the context of social relationships to support co-learning through 'co-constructed inquiry' (Keady et al., 2007).

By connecting with life histories in practice, reminiscence could support participants to move more deeply into the creative activities by using memories of the past as a vehicle for communication and social interaction in the present (Bruce and Schweitzer, 2008). People's life situations and lifelong experiences of learning were important context for this engagement. Negative experiences of school and concerns about being artistic could create barriers to engagement, whilst experiences of cognitive decline and assessment could create anxiety around 'getting it right', thereby reinforcing the potential for arts-based activities to create anxiety as well as enjoyment (Haslam et al., 2014). The co-construction of embodied interactions (Berendonk et al., in press) through which facilitators supported participants to connect with activities in ways that increased their confidence helped to reduce such anxiety.

Consequently, creative engagement could be supported by structuring sessions in a format that helped participants to feel a sense of mastery and competence from the outset, which reflects evidence from studies that have emphasised the importance of a strengths-based approach that connects with retained abilities and capacities (Windle et al., 2018b; Tietyen and Richards, in press). In addition to creating confidence amongst participants, seeing people with dementia engaged actively in learning new skills was helpful for promoting positive expectations amongst care staff and increasing their confidence in adopting new roles within their workplace (Guzmán-García et al., 2012). Supporting creative engagement relied on the confidence of the facilitator in leading arts-based activities, particularly if this was a new experience for them, reflecting the importance of facilitators' prior experiences given that they could also be concerned about their creative expertise.

The process of facilitation was a key element of co-constructing this new learning, including introducing activities at a pace that suited the individual and providing encouragement. Peers also had an important role in supporting new learning, in terms of offering encouragement to each other, and by enabling those who were unsure of the activities to first observe others participating before joining in. In 
this way, the group-based nature of the activity was helpful for increasing confidence, particularly as the shared nature of the activities helped people to be physically involved, so that people whose verbal communication was limited could participate and be included as part of the group. Humour played an integral part of social interactions. In previous research exploring arts-based engagement for people with dementia, humour has been identified as a means to avoid the need for the correct answer (Humphrey et al., in press). In the current study, humour was also observed being used as a way to subvert activities, which Bellass et al. (in press) link to the importance of recognising embodied expressions of resistance to engagement in order to support a truly participatory approach.

Reinforcing the importance of embodiment in the context of creativity (Kontos et al., 2017), arts-based activities were helpful in supporting engagement with nonverbal forms of expression (Hamill et al., 2011). Our findings support a framework of creativity that highlights engagement through meaningful physical and social interaction to create embodied learning, with many positive examples of participants informing, learning and expressing distinctiveness and relationality both verbally and non-verbally. Facilitators played an important role through developing supportive and participatory communicative strategies (Humphrey et al., in press). The co-construction of creative engagement also involved non-verbal relationality such as physically supporting the body of a person with mobility difficulties or creating art side-by-side in mutual enjoyment of the activities.

Affirming creative self-expression through both verbal and non-verbal interaction was therefore an important element of this co-constructed experience, reflecting Kontos and Grigorovitch's (2018) position that corporeality is a fundamental source of self-expression, interdependence and reciprocal engagement. Further, the group-based nature of the activities appeared to be particularly helpful in its capacity to affirm identities (Beard, 2011), with peer support of participants' contributions and outputs a significant element of this context. The importance of the facilitation process and the group dynamic in creating confidence and affirming creative self-expression reflects the relational nature of learning through arts-based engagement to support people with dementia to participate meaningfully (Ullán et al., 2011).

Most significantly, activities and conversations that were participant-led were most successful in sustaining creative engagement. Framing people with dementia as active partners in their care supports a model of relational citizenship that emphasises reciprocity and interdependence to promote agency and participation (Kontos et al., 2017). Therefore, in facilitating creative engagement, we argue that it is not the activity itself that should be in focus, rather the way in which the activity is co-constructed. We place importance on the relational context in which this interaction takes place and the participants, staff and volunteers who are involved. Every person participating, regardless of role, influences the interactions that are possible through the activities that are taking place.

\section{Conclusions}

Our findings demonstrate that people with dementia can continue to learn and grow through engagement in arts-based activities to produce positive outcomes 
for the individual participants as well as for the care staff who observe and participate in this creativity.

Creative engagement is embedded in the intersection between learner and context when experiencing new arts-based activities in a dementia care setting. In particular, people living with dementia may link new learning and creativity with a focus on a successful output, and therefore connect such activities to cognitive assessment, which may be particularly profound for people who experience processes of clinical assessment. Attention to lifelong experiences of learning and experiences of living with dementia are therefore important aspects of the wider context that need to be considered alongside the immediate interactional context when facilitating arts-based activities for people with dementia. We therefore call for more development and focus on the interactional elements, lifelong experiences, expectations and anxieties around performance in arts-based activities, for both participants and facilitators.

Whilst arts-based activities offer much potential in dementia care, awareness of past and present experiences that may impact on levels of engagement and confidence is necessary. While we did not explore the social demographics of participants in this study, Bellass et al. (in press) have highlighted that social inequalities may structure experiences of creative engagement and we concur this is a neglected dimension of the arts and dementia that would benefit from further research. Considering implications for practice, more attention to the wider context framing people's engagement with creative and arts-based activities should be built into the development and evaluation of interventions to embed critical reflection.

Author ORCIDs. (D) Jane M. Robertson 0000-0001-5973-957X

Acknowledgements. We gratefully acknowledge the participants, volunteers, staff and managers at the care home and day centre who generously gave their time and support for this project. We also thank the project steering group and our project partners who developed the toolkit. Many thanks to Emma Reynish and Catherine Hennessy who provided comments on drafts of this paper.

Financial support. This work was supported by a Scottish Funding Council Innovation Voucher (Project Code H08009). The funding sponsor played no part in the design, execution, analysis and interpretation of data, or writing of the study.

Ethical standards. The study received ethical approval from the University of Stirling School of Social Sciences Research Ethics Committee (reference number 100416). In addition, the project was approved by the research governance bodies of the participating care home and day centre (a local authority and a third-sector organisation, respectively).

\section{References}

Aspin DN, Evans K, Chapman J and Bagnall R (2012) Introduction and overview. In Aspin DN, Evans K, Chapman J and Bagnall R (eds), Second International Handbook of Lifelong Learning, Part 1. New York, NY: Springer, pp. x1v-xxxiv.

Basting A (2018) Building creative communities of care: arts, dementia, and hope in the United States. Dementia 17, 744-754.

Beard RL (2011) Art therapies and dementia care: a systematic review. Dementia 11, 633-656.

Bellass S, Balmer A, May V, Keady J, Buse C, Capstick A, Burke L, Bartlett R and Hodgson J (in press) Broadening the debate on creativity and dementia: a critical approach. Dementia. Available online doi:10.1177/1471301218760906. 
Berendonk C, Hnasen B, Randall WL, Baldwin C and Caine V (2017) Care as narrative practice in the context of long-term care: theoretical considerations. International Journal of Older People Nursing, 12, 12156. Available online at https://doi.org/10.1111/opn.12156 [30 May 2018].

Bienvenu B and Hanna G (2017) Arts participation: counterbalancing forces to the social stigma of a dementia diagnosis. AMA Journal of Ethics 19, 704-712.

Bourdieu P (1984) Distinction: A Social Critique of the Judgement of Taste. Cambridge, MA: Harvard University Press.

Braun V and Clarke V (2006) Using thematic analysis in psychology. Qualitative Health in Psychology 3, $77-101$.

Broome E, Dening T, Schneider J and Brooker D (2017) Care staff and the creative arts: exploring the context of involving care personnel in arts interventions. International Psychogeriatrics 29, 1979-1991.

Bruce E and Schweitzer P (2008) Working with life history. In Downs M and Bowers B (eds), Excellence in Dementia Care: Research into Practice. Maidenhead, UK: Open University Press, pp. 168-186.

Burnside LD, Knecht MJ, Hopley EK and Logsdon R (2017) here:now - Conceptual model of the impact of an experiential arts program on persons with dementia and their care partners. Dementia 16, 29-45.

Camic PM, Baker EL and Tischler V (2016) Theorizing how art gallery interventions impact people with dementia and their caregivers. The Gerontologist 56, 1033-1041.

Camic PM, Tischler V and Pearlman CH (2017) Viewing and making art together: a multi-session art-gallerybased intervention for people with dementia and their carers. Aging and Mental Health 18, 161-168.

Clift S (2012) Creative arts as a public health resource: moving from practice-based research to evidencebased practice. Perspectives in Public Health 132, 120-127.

Coleman P (1986) Ageing and Reminiscence Processes: Social and Clinical Implications. Chichester, UK: Wiley.

Crossick G and Kaszynska P (2016) Understanding the Value of Arts and Culture: The AHRC Cultural Value Project. Swindon, UK: Arts and Humanities Research Council. Available at http://www.ahrc.ac. uk/documents/publications/cultural-value-project-final-report/.

Daykin N, Gray K, McCree M and Willis J (2017) Creative and credible evaluation for arts, health and well-being: opportunities and challenges of co-production. Arts and Health 9, 123-138.

de Medeiros K and Basting A (2014) 'Shall I compare thee to a dose of Donepezil?' Cultural arts interventions in dementia care research. The Gerontologist 54, 344-353.

Dewey J (1963) Experience and Education. New York, NY: Collier Books.

Dewing J (2007) Participatory research: a method for process consent with persons who have dementia. Dementia 6, 11-25.

Dirkx JM (2001) The power of feelings: emotion, imagination and the construction of meaning in adult learning. In Merriam SB (ed.), The New Update on Adult Learning Theory (New Directions for Adult and Continuing Education No. 89). San Francisco, CA: Jossey-Bass, pp. 63-72.

Gillham B (2000) Case Study Research Methods. London: Continuum.

Gould VF (2013) Reawakening the Mind: Evaluation of Arts4Dementia's London Arts Challenge in 2012. London: Arts4Dementia. Available at https://www.arts4dementia.org.uk/reawakening-the-mind-report.

Goulding A (2013) A critical comparison of methods for evaluating arts and dementia programmes. Journal of Applied Arts 4, 133-149.

Grant D, Elliott J and Morrison S (2011) Holding eternity in an hour: a practical exploration of the arts in healthcare of older people with dementia. Journal of Applied Arts and Health 2, 237-255.

Gray K, Evans SC, Griffiths A and Schneider J (2018) Critical reflections on methodological challenge in arts and dementia evaluation and research. Dementia 17, 775-784.

Guzmán-García A, Mukaetova-Ladinska E and James I (2012) Introducing a Latin ballroom dance class to people with dementia living in care homes, benefits and concerns: a pilot study. Dementia 12, 523-535.

Hamill M, Smith L and Rohricht F (2011) 'Dancing down memory lane': circle dancing as a psychotherapeutic intervention in dementia - a pilot study. Dementia 11, 709-724.

Harries B (2013) The Storybox Project: Examining the Role of a Theatre and Arts-based Intervention for People with Dementia. London: Paul Hamlyn Foundation. Available at http://www.humanities.manchester.ac.uk/medialibrary/micra/events/2013/Storybox_Project.pdf.

Haslam C, Haslam SA, Ysseldyk R, McCloskey L, Pfisterer K and Brown SG (2014) Social identification moderates cognitive health and well-being following story- and song-based reminiscence. Aging and Mental Health 18, 424-434. 
Heaton J (1998) Secondary analysis of qualitative data. Social Research Update 22. Available at http://sru. soc.surrey.ac.uk/SRU22.html.

Humphrey J, Montemuro M, Coker E, Kilgour-Walsh L, Moros K, Murray C and Stanners S (in press) Artful moments: a framework for successful engagement in an arts-based programme for persons in the middle to late stages of dementia. Dementia. Available online doi:10.1177/1471301218776780.

Keady J, Williams S and Hughes-Roberts J (2007) 'Making mistakes': using co-constructed inquiry to illuminate meaning and relationships in the early adjustment to Alzheimer's disease - a single case study approach. Dementia 6, 343-364.

Killick J and Allan K (2001) Communication and the Care of People with Dementia. Buckingham, UK: Open University Press.

Knowles MS, Holton EF and Swanson RA (2011) The Adult Learner, 7th Edn. Houston, TX: Gulf.

Kontos P (2004) Ethnographic reflections on selfhood, embodiment and Alzheimer's disease. Ageing \& Society 24, 829-849.

Kontos P and Grigorovitch A (2018) Rethinking musicality in dementia as embodied and relational. Journal of Aging Studies 45, 39-48.

Kontos P, Miller KL and Kontos AP (2017) Relational citizenship: supporting embodied selfhood and relationality in dementia care. Sociology of Health and Illness 39, 182-198.

Mackenzie J (2009) 'The same but different': working with lesbian and gay people with dementia. Journal of Dementia Care 17, 6, 17-19.

Mental Health Foundation (2015) Dementia, Rights, and the Social Model of Disability: A New Direction for Policy and Practice? London: Mental Health Foundation.

Merriam SB and Bierema LL (2013) Adult Learning: Linking Theory and Practice. San Francisco, CA: Jossey-Bass.

Miles A and Gibson L (2016) Everyday participation and cultural value. Cultural Trends 25, 151-157.

Noice T, Noice H and Kramer AF (2014) Participatory arts for older adults: a review of benefits and challenges. The Gerontologist 54, 741-753.

Nyström K and Lauritzen SO (2005) Expressive bodies: demented persons' communication in a dance therapy context. Health: An Interdisciplinary Journal for the Social Study of Health, Illness and Medicine 9, 297-317.

Scottish Government (2016) The Scottish Index of Multiple Deprivation. Available at http://www.gov.scot/ Topics/Statistics/SIMD.

Spradley JP (1980) Participant Observation. Long Grove, IL: Waveland Press.

Stolz SA (2015) Embodied learning. Educational Philosophy and Theory 47, 474-487.

Tietyen AC and Richards AG (in press) A Visual Arts Education pedagogical approach for enhancing quality of life for persons with dementia (innovative practice). Dementia. Available online doi:10.1177/1471301217726612.

Ullán AM, Belver MH, Badíal M, Moreno C, Garrido E, Gómez-Isla J, Gonzalez-Ingelmo E, Delgado J, Serrano I, Herrero C, Manzanera P and Tejedor L (2011) Contributions of an artistic educational program for older people with early dementia: an exploratory qualitative study. Dementia 12, 425-446.

Windle G, Gregory S, Howson-Griffiths T, Newman A, O'Brien D and Goulding A (2018a) Exploring the theoretical foundations of visual arts programmes for people living with dementia. Dementia 17, $702-727$.

Windle G, Joling K J, Howson-Griffiths T, Woods B, Hedd Jones C, van de Ven P M, Newman A and Parkinson C (2018b) The impact of a visual arts program on quality of life, communication, and wellbeing of people living with dementia: a mixed-methods longitudinal investigation. Dementia 30, 409-423.

Young R, Camic PM and Tischler V (2016) The impact of community-based arts and health interventions on cognition in people with dementia: a systematic literature review. Aging and Mental Health 20, 337-351.

Zeilig H, Killick J and Fox C (2014) The participative arts for people living with a dementia: a critical review. International Journal of Ageing and Later Life 9, 7-34.

Cite this article: Robertson JM, McCall V (2020). Facilitating creativity in dementia care: the co-construction of arts-based engagement. Ageing \& Society 40, 1155-1174. https://doi.org/10.1017/ S0144686X18001575 